\title{
Microgrid Economic Operation Research Based on Improved Particle Swarm Optimization Algorithm
}

\author{
Xueying Wang ${ }^{1,}$, , Peng $\mathrm{Li}^{1}$ \\ ${ }^{1}$ State Key Laboratory of Alternate Electrical Power System with Renewable Energy Sources, \\ North China Electric Power University, Baoding 071003, Hebei, China
}

awangxueying1991@foxmail.com Keywords: distributed generation, microgrid, economic operation, the improved particle swarm
operation (PSO) algorithm

\begin{abstract}
This paper presents a new optimization approach for solving the economic operation with consideration of wind, solar, micro-turbine, fuel cells, battery and load in an energy system. Mathematical models of each micro source and the system model of the microgrid economic operation are established, and the system model is solved by improved particle swarm optimization (PSO) algorithm. The best output of each micro source and energy storage unit and the lowest operating cost comparing by improved PSO is compared with the traditional PSO. The MATLAB simulation indicates the high speed and accuracy of the improved PSO, and verifies the effectiveness of the model.
\end{abstract}

\section{Introduction}

In recent years, clean energy and distributed generation is attracting extensive attention all over the world [1,2]. People begin to put forward the application of distributed generation, and the microgrid also arises. Microgrid economic operation is one of the most important problems of microgrid research. Through scheduling the output of distributed power and energy storage unit in microgrid, the energy efficiency can be improved a lot and the power generation cost and system discharge can be reduced in some degree under the demand of enough electric power [3].

Literature [4] analyzed microgrid economic operation models of different constraint conditions. Literature [5] studied the optimal allocation of energy according to various distributed energy resources (DER). Literature [6] studied microgrid economic operation models in island and calculated the model by generic algorithm.

Microgrid optimal operation is a kind of dynamic multidimensional nonlinear optimization problems, and it needs for quick search to the global optimal point. The commonly methods including mathematics analytic method, particle swarm optimization (PSO) algorithm, ant colony algorithm, genetic algorithm (GA), evolutionary algorithms, etc. [7-10].

This article made a research for a microgrid system which contains windturbine (WT), photovoltaic (PV), fuel cell (FC), micro-turbine (MT), storage battery (SB) and electrical load. And it built a microgrid economic operation model in meeting the constraint conditions of energy balance between supply and demand, power quality and more. Each micro source output and the optimal object under the parallel operation considering the real-time electric price is calculated by using improved PSO. And the optimization results is compared with the traditional PSO.

\section{Micro Source Modeling}

In this section this paper did not analyze windturbine (WT) and photovoltaic (PV) because of its characteristics of randomness and intermittent. And the distribution characteristics of WT and PV are analyzed according to historical data.

Fuel Cell. The daily cost calculation formula of fuel cell is formulated as follows:

$$
C_{F C}=c \cdot T \frac{1}{L H V} \cdot \sum_{F C} \frac{P_{F C}}{\eta_{F C}}
$$




$$
\eta_{J}=-0.0023 P_{J}+0.6735
$$

where $C_{F C}$ is the operation cost of fuel cell; $T$ is the fuel operation time; $L H V$ is the low calorific value of gas; $c$ is the fuel price; $P_{F C}$ is the static power output; $\eta_{F C}$ is the efficiency of fuel cell.

Micro Gas Turbine. Its daily cost calculation formula is similar to fuel cell.

$$
\begin{aligned}
C_{M T} & =c \cdot T \frac{1}{L H V} \cdot \sum_{M T} \frac{P_{M T}}{\eta_{M T}} \\
\eta_{M T} & =0.0753\left(\frac{P_{M T}}{65}\right)^{3}-0.3095\left(\frac{P_{M T}}{65}\right)^{2}+0.4174\left(\frac{P_{M T}}{65}\right)+0.1068
\end{aligned}
$$

where $C_{M T}$ is the operation cost of micro gas turbine; $P_{M T}$ is the micro gas turbine power output; $\eta_{M T}$ is the efficiency of micro gas turbine.

Storage Battery. The charging and discharging of storage battery under the parallel operation is not only restricted by the performance requirements, but also affected by electricity peak and valley. Battery only works in electricity peak and valley.

\section{Microgrid Economic Operation Modeling}

This paper mainly analyzed the optimization of the lowest costs on conditions of the active power balance, the limitation of distributed power output and the limitation of battery storage capacity.

Objective Function. Microgrid as an independent whole under the parallel operation can purchase power from the external grid when its internal power is not enough to meet the requirements of the internal loads, and it also can send power to the grid. The economic operation problem can be formulated as follows:

$$
\min F(x)=\sum_{t=1}^{T}\left[C_{F}+C_{O M}+C_{S C}+C_{B U Y}-C_{S E L L}\right]
$$

where $F(x)$ is the generating cost; $T$ is the number of times for scheduling cycle; $C_{F}$ is the fuel cost; $C_{O M}$ is the operation maintenance cost; $C_{S C}$ is the start-up cost of micro gas turbine and fuel cell; $C_{B U Y}$ and $C_{S E L L}$ is the power purchase cost and the power sell cost respectively.

a) Fuel cost $\left(C_{F}\right)$

$$
C_{F}=C_{F C}+C_{M T}
$$

Only power units which consume fossil fuel such as fuel cells and micro gas turbines consider fuel cost.

b) Operation maintenance cost $\left(C_{O M}\right)$

$C_{\text {OM.G }}=c_{G} \times P_{G}$

where $C_{O M . G}$ is the operation maintenance cost of each micro source; $c_{G}$ is the operation maintenance coefficient of each micro source; $P_{G}$ is the power output of each micro source.

c) Start-up cost $\left(C_{S C}\right)$

Fuel cell and micro gas turbine have the similar operation characteristics of start-stop quality and the controllable generating. So the start-up cost can be ignored.

\section{Constraint Conditions.}

a) Power balance

$$
\sum_{i=1}^{n} P_{W T}(t)+\sum_{j=1}^{n} P_{P V}(t)+\sum_{k=1}^{n} P_{M T}(t)+\sum_{l=1}^{n} P_{F C}(t)+P_{G r i d}(t)+\operatorname{pbat}(t)=P_{D}(t)
$$

where $P_{W T}(t), P_{P V}(t), P_{M T}(t)$ and $P_{F C}(t)$ are the power output of windturbine, photovoltaic, fuel cell, micro-turbine for the $t$ moment respectively; $i, j, k$ and $l$ are the number of the micro source respectively; $P_{\text {Grid }}(t)$ is the interactive power between microgrid and the network for the $t$ moment; $\operatorname{pbat}(t)$ is the interactive power between battery and the network for the $t$ moment; $P_{D}(t)$ is the microgrid load for the $t$ moment.

b) Interactive power constraints between microgrid and network

$$
P_{\text {Grid,min }}(t) \leq P_{\text {Grid }}(t) \leq P_{\text {Grid,max }}(t)
$$


where $P_{G r i d, \min }(t)$ and $P_{\text {Grid,max }}(t)$ are the minimum and the maximum interactive power between microgrid and network.

c) Active output constraints of WT and MT

$P_{G, \text { min }} \leq P_{G}(t) \leq P_{G, \max }$

where $P_{G}(t)$ is micro source (WT, MT) power for the $t$ moment; $P_{G \text {,min }}$ and $P_{G \text {,max }}$ are the upper and lower of micro source active power.

d) Constraints of battery operating

$$
\begin{aligned}
& \text { pbat }_{\text {initial }}=0.4 b a t \\
& \text { bat }_{\min } \leq \text { bat }(t) \leq b a t_{\max } \\
& \text { pbat }_{\min } \leq \text { pbat }(t) \leq \text { pbat }_{\max }
\end{aligned}
$$

where bat is the battery capacity; pbat initial $_{\text {is }}$ the initial capacity of the battery; bat $(t)$ is the battery capacity for the $t$ moment; $b a t_{\min }$ and $b a t_{\max }$ are the lowest and highest capacity battery allowed respectively; $\operatorname{pbat}(t)$ is the interactive power between battery and microgrid for the $t$ moment; pbat $_{\min }$ and pbat $_{\max }$ are the minimum and maximum power when charge or discharge the battery respectively.

\section{Analysis of Examples}

This paper made an analysis for a specific network which is shown in figure 1:

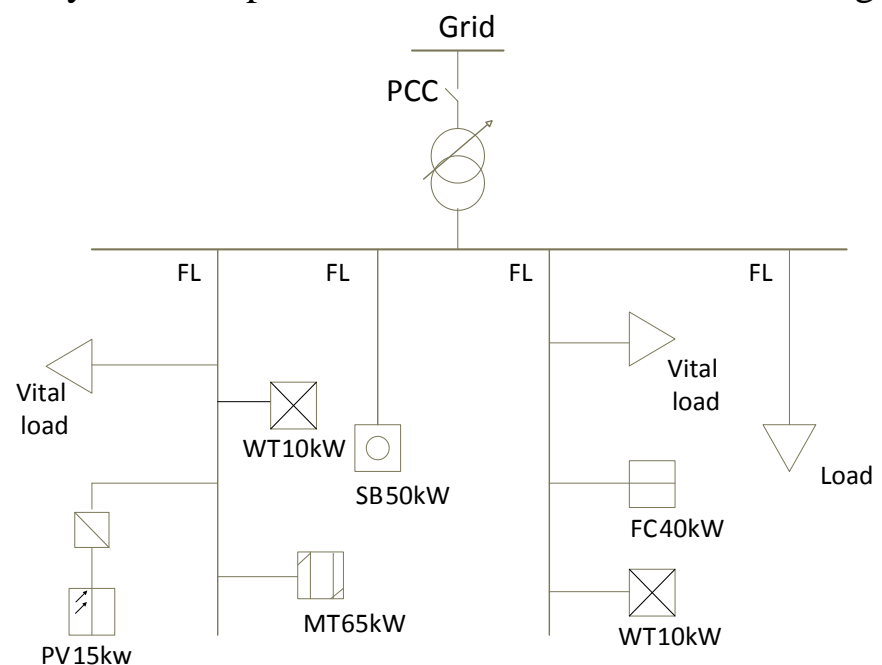

Fig.1. The schematic of microgrid system

Basic Data. The generation fuel of FC and MT adopt gas which price is $\$ 0.7 \mathrm{~m}^{3}$; its $L H V_{f}$ is 9.7 $\mathrm{KW} \bullet \mathrm{m}^{3}$.

Table 1. The parameters of each micro source

\begin{tabular}{|c|c|c|c|c|c|c|}
\hline Micro source type & WT & PV & FC & MT & SB & Grid \\
\hline Operation maintenance coefficient & 0.0296 & 0.0096 & 0.0275 & 0.0825 & 0 & 0 \\
\hline Power upper [kW] & 0 & 0 & 0 & 0 & -30 & -100 \\
\hline Power lower [kW] & 10 & 15 & 40 & 65 & 30 & 100 \\
\hline
\end{tabular}

The Analysis of Results. The daily load curve and the PV, WT output within 24 hours are obtained from the load forecasting and the experience. The output curves of each micro source within 24 hours solved by traditional PSO and improved PSO respectively is as follows: 


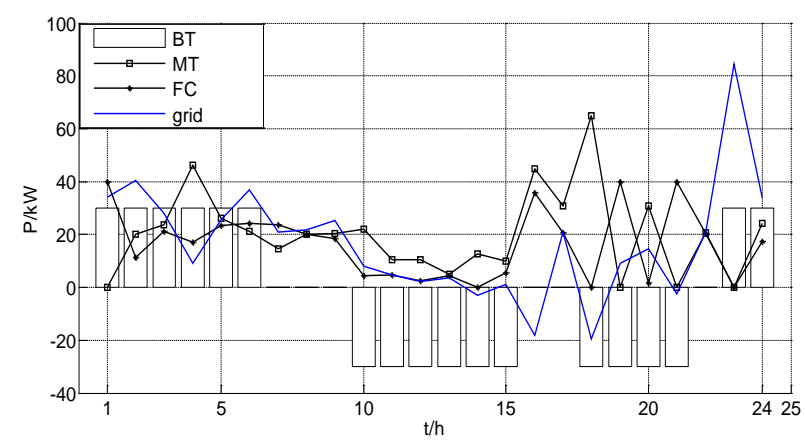

Fig.2. The curve of micro source output within 24 hours (before improvement )

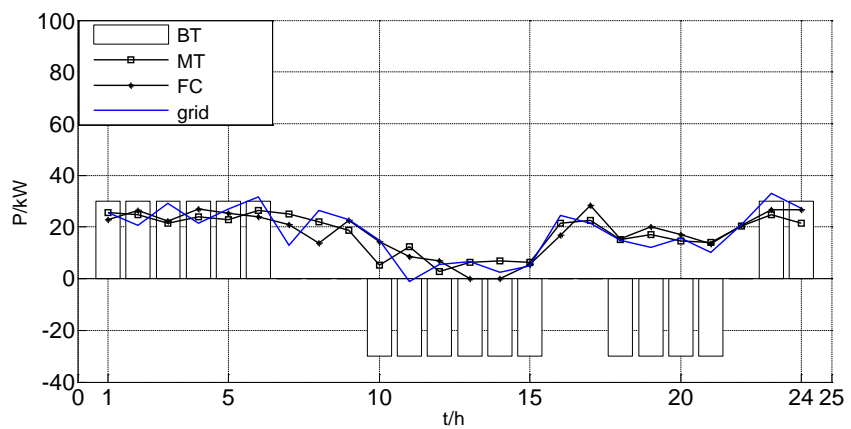

Fig.3. The curve of micro source output within 24 hours (after improvement ) The data contrast between traditional PSO and improved PSO is shown in the following table:

Table 2. The data contrast between traditional PSO and improved PSO

\begin{tabular}{|c|c|c|}
\hline & Traditional PSO & Improved PSO \\
\hline Operation speed [s] & 10.889945 & 6.650729 \\
\hline Operation result [\$] & 792.9024 & 754.1277 \\
\hline
\end{tabular}

From what has been discussed above, the advantages of improved PSO can be discussed from two aspects:

1) From the aspect of algorithm performance, the speed of data processing by iterative operation can be improved significantly. So the improved PSO can improve operation efficiency of the model and save time in some degree. The more the number of interactions, the more obvious the performance is.

2) From the aspect of system, the improved PSO optimized the precision of data processing, further more, it improved the operation result. Besides, it reduced the comprehensive cost and improved the energy efficiency for saving the cost. At the same time, the curve of micro source output solved by improved PSO is smoother, which shows that the micro source output is relatively flat. So it can reduce the damage to the microgrid components and improve the quality of the user's electricity.

\section{Conclusion}

This paper built a microgrid economic operation model, including the model of each micro source (fuel cell, micro gas turbine), energy storage device (battery) and the electricity trading between microgrid and network. The mutually independent problems including the power scheduling of generator set, the intelligent management of energy storage device, and the operation problem of grid operation are transformed into a single optimization problem, which reduced the complexity of optimization algorithm. By improving the traditional PSO through iterative optimization for model solving, it improved the data processing speed for the high operation efficiency. Besides, the improved PSO improved the output curve of each micro source and made it more flat, which reduced the damage to microgrid components, improved the electricity quality of the users and reduced the comprehensive cost of microgrid. 


\section{References}

[1] H. B.Puttgen, P. R.Macgregor, F. C. Lambert. Distributed generation: semantic hype of the dawn of a new era[J]. IEEE Power and Energy Magazine, 2003, 1(1):22-29.

[2] A. Khodaei. Microgrid Optimal Scheduling With Multi-Period Islanding Constraints[J]. IEEE Transactions on Power Systems, 2004, 29(3):1383-1392.

[3] A. Saber, G. Venayagamoorthy. Plug-in vehicles and renewable energy sources for cost and emission reductions[J]. IEEE Transactions on Industrial Electronics, 2011, 58(4):1229-1238.

[4] F. Katiraei, M.R. Iravani, P. W. Lehn. Micro-grid autonomous operation during and subsequent to islanding process[J]. IEEE Transactions on Power Delivery, 2005,V20(1):248-257.

[5] S. Mizani, A. Yazdani. Optimal design and operation of a grid-connected microgrid [C]. IEEE Electrical Power and Energy Conference, 2009:1-6.

[6] F. Mohammad, B. Hassan. Adaptive Energy Consumption Scheduling for Connected Microgrids Under Demand Uncertainty[J]. IEEE Transactions on power delivery, 2013, 28(3):1576-1583.

[7] Y. Jie, Z.J. Wu, S. Bhattacharya. Power Dispatch Strategy in Microgrid Integrated with Solid State Transformer[C]. Proceedings of IEEE Power Engineering Society General Meeting, 2013:1-5.

[8] S. Campanari, E. Macchi. Technical and tariff scenarios effect on micro-turbine trigenerative applications[J]. Journal of Engineering for Gas Turbines and Power, 2004,126(3):581-589.

[9] F. Katiraei, M.R. Iravani. Power Management Strategies for a Microgrid With Multiple Distributed Generation Units[J]. IEEE Transactions on Power Systems, 2006, 21(4):1821-1831.

[10] Chen C., DuanS, CaiT, et al. Smart energy management system for optimal microgrid economic operation[J]. IET Renewable Power Generation, 2011, 5(3):258-267. 